OPEN ACCESS

Edited by:

Panteleimon Giannakopoulos, Université de Genève, Switzerland

Reviewed by:

Luis Beltran-Parrazal,

Universidad Veracruzana, Mexico

Frank Richter

University Hospital Jena, Germany

${ }^{*}$ Correspondence:

Rubem Carlos Araújo Guedes guedes.rca@gmail.com

Received: 30 October 2018 Accepted: 21 May 2019 Published: 07 June 2019

Citation:

Guedes RCA and Abadie-Guedes R (2019) Brain Aging and Electrophysiological Signaling: Revisiting the Spreading Depression

\section{Brain Aging and Electrophysiological Signaling: Revisiting the Spreading Depression Model}

\author{
Rubem Carlos Araújo Guedes ${ }^{*}$ and Ricardo Abadie-Guedes² \\ ${ }^{1}$ Departamento de Nutrição, Universidade Federal de Pernambuco, Recife, Brazil, ${ }^{2}$ Departamento de Fisiologia e \\ Farmacologia, Universidade Federal de Pernambuco, Recife, Brazil
}

As a consequence of worldwide improvement in health care, the aging portion of the human population has increased, now representing a higher proportion of the total population. This fact raises great concern regarding how to age while maintaining good brain function. Very often, alterations in brain electrophysiological signaling are associated with age-dependent functional disorders of the brain. Therefore, animal models suitable for the study of age-related changes in electrical activity of the brain can be very useful. Herein, we review changes in brain electrophysiological features as a function of age by analyzing studies in the rat brain on the phenomenon known as cortical spreading depression (CSD). Alterations in the brain's capability to generate and propagate CSD may be related to differences in the propensity to develop certain neurological diseases, such as epilepsy, stroke, and migraine, which can biunivocally interact with the aging process. In this review, we revisit ours and others' previous studies on electrophysiological features of the CSD phenomenon, such as its velocity of propagation and amplitude and duration of its slow negative DC shift, as a function of the animal age, as well as the interaction between age and other factors, such as ethanol consumption, physical exercise, and nutritional status. In addition, we discuss one relatively new feature through which CSD modulates brain signaling: the ability to potentiate the brain's spontaneous electrical activity. We conclude that the CSD model might importantly contribute to a better understanding of the aging/brain signaling relationship.

\section{Keywords: aging, alcohol abuse, brain excitability, exercise, malnutrition, spreading depression}

\section{INTRODUCTION: AGING AND BRAIN FUNCTION}

A growing percentage of the human population is presently living longer than in past centuries. Because of this, the current health authorities are increasingly concerned about how to maintain normal functionality while becoming older (World Health Organization [WHO], 2015), and this includes avoiding, or at least minimizing, the negative effects of the aging process on brain function. Compared with younger people, the elderly population is at a higher risk for stroke (Zhou et al., 2018), disturbances of neurovascular processes (Bell et al., 2010), single cell structure and electric alterations (Coskren et al., 2015), and cognitive function disorders (Hernandez et al., 2018). Evidence also suggests that brain-guided sensory-motor activity can be substantially impaired by the aging process (Anguera and Gazzaley, 2012; Bernard and Seidler, 2014). 
In this review, we revisit the theme of the influence of aging on electrophysiological aspects of brain signaling as indexed by the excitability-related phenomenon known as cortical spreading depression (CSD; Guedes et al., 1996; Farkas et al., 2011; Sousa et al., 2018). In addition, we examine how aging interacts with other factors, such as alcohol consumption (Abadie-Guedes et al., 2016), physical exercise, and nutritional status (Batista-de-Oliveira et al., 2012; Silva-Gondim et al., 2017), regarding the brain's capability of generating and propagating CSD, which has been continuously investigated in our laboratory for many years (see Guedes, 2005, 2011; Abadie-Guedes et al., 2016, for an overview). Using the CSD phenomenon, we previously studied the action of chronic ethanol administration via gavage on treadmill/swimming exercise and early nutritional deficiencies in the brain of albino rats at various ages. Our findings support and highlight the usefulness of the CSD model in studying age-related alterations in the brain's electrophysiological features, as we will detail in the subsequent sections of this review.

\section{INFLUENCE OF AGING ON THE BRAIN'S ELECTRICAL ACTIVITY}

In mammals, including humans, cells in the normal brain exert their various functions by generating and propagating electrical activity. Digitalization, storage, and analysis of brain electrical signals can be achieved by electronic devices based on microchipoperated circuits and appropriate software programs (Guedes, 2005; Coskren et al., 2015; Silva-Gondim et al., 2017). In many clinical cases, detection of an altered EEG-pattern helps diagnose epileptic and non-epileptic neurological disorders (Asadi-Pooya et al., 2017). Studies on the features of brain electrical activity have indicated that some alterations are age-dependent. For example, in Rhesus monkeys, somatosensory, visual, and auditory evoked electric responses are delayed in aged animals compared to young controls (Ibáñez-Contreras et al., 2018), and computational models using data from whole cell patch-clamp recordings and high-resolution digital reconstruction of neurons suggest increased firing rates in aged subjects (Coskren et al., 2015). Studies in humans also demonstrate age-related EEG (Watson et al., 2012) and evoked potential changes (Bourisly and Shuaib, 2018). Supplementary Table S1 presents examples of brain morphological and physiological features that change as a function of aging.

The effects of aging on the brain's electrical activity are attributed to several factors, including alterations in brain vasculature (Guo et al., 2018; McKetton et al., 2018) and transmitter systems (Schliebs and Arendt, 2011; Hernandez et al., 2018), as well as free radical-induced injury to brain cells as a consequence of redox imbalance (Carvalho and Moreira, 2018), among others. The impact of redox imbalance is considerably significant, as the brain demands as much as $20 \%$ of an organism's oxygen in order to function normally (Guillemin et al., 2017). This implies a high susceptibility of brain cells to oxidative injury (Guillemin et al., 2017), which seems to increase the risk for cerebrovascular-based brain diseases (Seals et al., 2014).

\section{ELECTROPHYSIOLOGICAL EFFECTS OF AGING: STUDIES USING THE SPREADING DEPRESSION MODEL}

The phenomenon known as cortical spreading depression (CSD) was first described by the Brazilian scientist Aristides A. P. Leão (1944a). During the recording of brain electrical activity in anesthetized rabbits, Leão first noted that a strong electric stimulation of a point on the cortical surface produced a reversible reduction (depression) of the electrocorticographic waves, which recovers completely after a few minutes. From the stimulated cortical point, CSD reversibly propagates in all directions to increasingly remote cortical regions. In a second publication in the same year (Leão, 1944b), this author documented that vasodilation of cortical blood vessels accompanied CSD. Three years later (Leão, 1947), the author described a direct current (DC) slow potential change that appeared in the depressed cortical tissue and that was measured in relation to a remote reference point. This slow, all-or-none type DC signal is considered the hallmark of CSD. According to current data on animal and human experiments, the brain's electrical silence of CSD is caused by neuronal and glial depolarization (Hartings et al., 2017). CSD propagation velocity over the cortical tissue is paradoxically very low, on the order of $2-5 \mathrm{~mm} / \mathrm{min}$, in contrast with the much faster propagation velocity of neuronal action potentials, on the order of tens of $\mathrm{m} / \mathrm{s}$ (Guedes et al., 2016). SD has been documented in all species so far investigated, from fishes (Young, 1980) to humans (Lauritzen and Strong, 2017), which suggests a role for this phenomenon in the normal brain. On the other hand, CSD has been related to brain pathophysiology (Lauritzen and Strong, 2017; Dreier et al., 2018). Some important neurological disorders are postulated as having CSD causally participating in their pathogenesis. This is the case for migraines, traumatic brain injury (Lauritzen, 1987; Hartings et al., 2009, 2011; Torrente et al., 2014; Sadeghian et al., 2018; Vinogradova, 2018), subarachnoid hemorrhage (Dreier et al., 2006, 2009) epilepsy (Guedes and Cavalheiro, 1997; Mesgari et al., 2017), and stroke (Takano et al., 1996; see Lauritzen and Strong, 2017 for an overview). A number of nutritional, pharmacologic, environmental, and hormonal manipulations are shown to either increase or decrease CSD velocity of propagation compared to control animals (Guedes, 2011; Guedes et al., 2017). These pieces of evidence support the conclusion that CSD velocity of propagation is a useful index to evaluate electrophysiological aspects of brain signaling. Table 1 presents some animal and human studies on CSD characteristics as a function of age.

\section{Age Correlates Negatively With CSD Propagation}

Our group has dedicated considerable effort investigating how the age of an organism influences its brain's ability to propagate CSD. In our pioneer study (Guedes et al., 1996), we documented the CSD propagation velocity in rats as a function of the animal's age. We found that CSD velocity significantly decreased as the animal's age increased. Figure 1A illustrates these data, demonstrating a significant reduction of CSD velocity 
in 7-12-month-old and 13-18-month-old Sprague-Dawley rats compared to younger (4-6-month-old) animals. This negative correlation was also found in Wistar rats and in another rodent species, the Mongolian gerbil (Meriones unguiculatus), suggesting that the age effect on CSD is neither a particular feature of one rat strain, nor a species-specific characteristic (Guedes et al., 1996). Furthermore, dietary deficiency of antioxidant vitamins enhances CSD velocity more in old than in young groups (Figure 1A, right panel), suggesting the involvement of age-related mechanisms based on redox imbalance in the aged brain.

These data, which indicated an inverse correlation between age and CSD susceptibility, have been confirmed by various reports (e.g., Farkas et al., 2011; Batista-de-Oliveira et al., 2012). In rats, an age-dependent diminished frequency of $\mathrm{K}^{+}$-induced
SDs and an increased latency between subsequent SD events have also been reported (Farkas et al., 2011). In humans who suffered acute brain injury, spontaneous SD episodes are reportedly less frequent in old compared to younger patients (Fabricius et al., 2006). When considered together, these data support the hypothesis of lower SD susceptibility in the aged brain.

\section{Age, Ethanol Consumption, and CSD Features}

Increased generation of reactive oxygen species (ROS) in the nervous tissue seems to modulate CSD susceptibility (Netto and Martins-Ferreira, 1989; El-Bachá et al., 1998; Mendes-da-Silva et al., 2014). A scenario of increased ROS production is certainly

TABLE 1 | Some studies involving aging and CSD.

\begin{tabular}{|c|c|c|c|}
\hline \multicolumn{4}{|c|}{ Examples of studies illustrating some effects of aging on spreading depression } \\
\hline Species & $\begin{array}{l}\text { References (in } \\
\text { alphabetical order) }\end{array}$ & Condition & Main outcomes \\
\hline Rat & Abadie-Guedes et al., 2016 & $\begin{array}{l}\text { The authors recorded CSD in rats of two } \\
\text { age-ranges that received acute or chronic } \\
\text { ethanol }(E) \text {, with or without alpha-tocopherol }(T)\end{array}$ & $\begin{array}{l}\text { Increasing age decelerated CSD. E influenced } \\
\text { CSD on both ages. T counteracts the ethanol } \\
\text { effects on CSD }\end{array}$ \\
\hline Rat & Barreto et al., 2014 & $\begin{array}{l}\text { The authors reviewed the action of ethanol } \\
\text { consumption on CSD }\end{array}$ & $\begin{array}{l}\text { The authors postulate that some of the ethanol } \\
\text { effects are related with mitochondrial } \\
\text { dysfunction with aging }\end{array}$ \\
\hline Rat & $\begin{array}{l}\text { Batista-de-Oliveira et al., } \\
2012\end{array}$ & $\begin{array}{l}\text { The authors investigated whether physical } \\
\text { exercise, lactation conditions, and aging } \\
\text { interact and modulate brain electrophysiology } \\
\text { as indexed by CSD }\end{array}$ & $\begin{array}{l}\text { An aging-related CSD deceleration was } \\
\text { observed. Unfavorable lactation facilitated CSD, } \\
\text { while treadmill exercise impaired it. Failure to } \\
\text { elicit CSD by } \mathrm{KCl} \text { was greater in older rats }\end{array}$ \\
\hline Rat & Clark et al., 2014 & $\begin{array}{l}\text { The authors characterized the SD in young, } \\
\text { middle-aged, and old rats after middle cerebral } \\
\text { artery occlusion, utilizing multimodal imaging } \\
\text { with voltage-sensitive dyes }\end{array}$ & $\begin{array}{l}\text { Age reduced the number of SDs but increased } \\
\text { the size of ischemic area displaying prolonged } \\
\text { SD. The growth of area generating SD positively } \\
\text { correlated with the ischemic core area }\end{array}$ \\
\hline Human & Fabricius et al., 2006 & $\begin{array}{l}\text { Electrographic recordings that were identical to } \\
\text { Leao's CSD, were recorded in acutely } \\
\text { brain-injured human patients with various ages }\end{array}$ & $\begin{array}{l}\text { CSDs in acute brain disorders occur at lower } \\
\text { incidence in older patients than in younger ones }\end{array}$ \\
\hline Various & Farkas and Bari, 2014 & $\begin{array}{l}\text { The author reviewed studies on animals and } \\
\text { humans relating the SD in the ischemic brain } \\
\text { with the age of the organism }\end{array}$ & $\begin{array}{l}\text { The authors hypothesize that augmentation of } \\
\text { the ischemic lesion in the elderly patients is } \\
\text { age-dependent }\end{array}$ \\
\hline Rat & Farkas et al., 2011 & $\begin{array}{l}\text { CSD recording in rats of various ages and brain } \\
\text { hypoperfusion }\end{array}$ & $\begin{array}{l}\text { The data suggested a reduced sensitivity of the } \\
\text { cortex to CSD elicitation with early aging, and a } \\
\text { less responsive cerebrovascular system with } \\
\text { chronic hypoperfusion }\end{array}$ \\
\hline Rat & Guedes et al., 1996 & $\begin{array}{l}\text { Evaluation of cortical spreading depression } \\
\text { (CSD) propagation in rats and gerbils of various } \\
\text { ages }\end{array}$ & $\begin{array}{l}\text { In both species, older animals displayed lower } \\
\text { CSD velocities than younger ones; deficiency of } \\
\text { dietary antioxidant vitamins abolished this effect }\end{array}$ \\
\hline Rat & Hertelendy et al., 2017 & $\begin{array}{l}\text { In } 38 \text { rats ( } 7-30 \text { week-old), CSD was } \\
\text { documented by ECoG and DC potential } \\
\text { recording }\end{array}$ & $\begin{array}{l}\text { Advancing age and ischemia elevate the } \\
\text { electric threshold to elicit CSD }\end{array}$ \\
\hline Rat & Menyhárt et al., 2015 & $\begin{array}{l}\mathrm{KCl} \text {-induced SD after bilateral common carotid } \\
\text { artery occlusion was studied in young and old } \\
\text { rats. ECoG, DC potential, and cerebral blood } \\
\text { flow (CBF) variations were acquired }\end{array}$ & $\begin{array}{l}\text { Ischemia and age delayed the recovery from } \\
\text { SD. CBF decreased during ischemia in the old } \\
\text { animals, and inverse neurovascular coupling } \\
\text { with SD evolved in the old ischemic group }\end{array}$ \\
\hline Rat & Menyhárt et al., 2017 & $\begin{array}{l}\text { CSD was recorded in 2-months, and } \\
18-20 \text { months old rats under ischemia and } \\
\text { reperfusion }\end{array}$ & $\begin{array}{l}\text { Old age changes CSD parameters and its } \\
\text { relation with ischemia, suggesting a kind of } \\
\text { metabolic dysfunction in the older brain }\end{array}$ \\
\hline Rat & Sousa et al., 2018 & $\begin{array}{l}\text { Adult young and aged rats received a powder } \\
\text { extract of murici fruit, which is antioxidant. CSD } \\
\text { was recorded and oxidative stress was } \\
\text { biochemically evaluated }\end{array}$ & $\begin{array}{l}\text { Aging decreased CSD propagation, catalase } \\
\text { activity and glutathione/oxidized glutathione } \\
\text { ratio; increased malondialdehyde } \\
\text { concentrations and SOD activity }\end{array}$ \\
\hline
\end{tabular}


A

\section{3-18 mo. old}

\section{7-12 mo. old}

4-6 mo. old

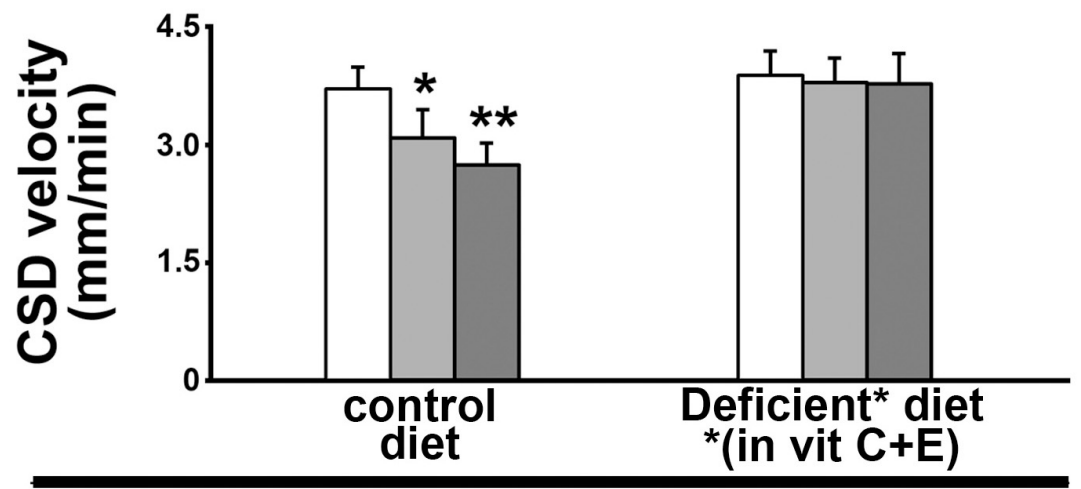

B

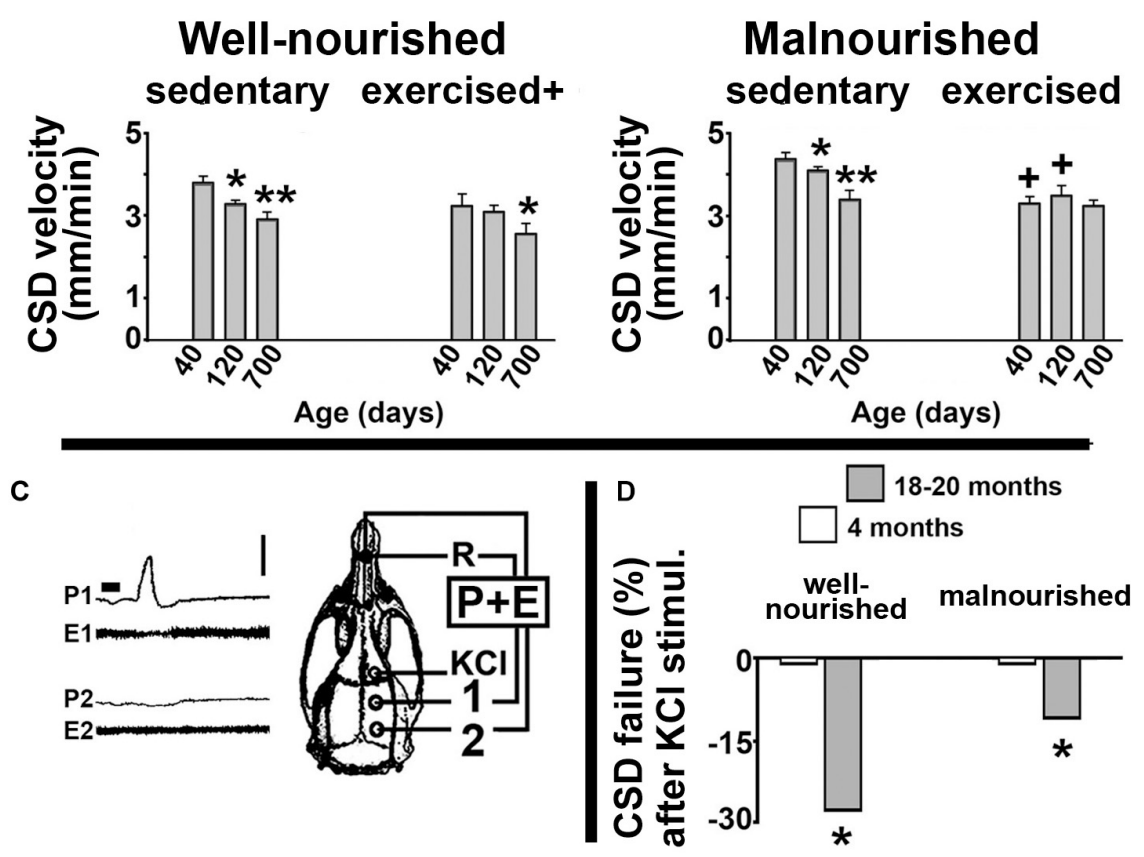

FIGURE 1 | (A) Propagation velocity (in $\mathrm{mm} / \mathrm{min}$ ) of cortical spreading depression (CSD) measured in rats from three age groups: 4-6-month, 7-12-month, and 13-18-month-old animals. Data are the means \pm standard deviations from eight animals per age group. The inverse correlation between CSD velocity and age (left panel) disappeared when animals were fed a diet that was deficient in the antioxidant vitamins $C$ and $E$ (right panel). ${ }^{*} p<0.05$ compared to the 4-6-month-old group. ${ }^{* *} p<0.005$ compared to the two younger age-groups (ANOVA plus Holm-Sidak test). The skull diagram illustrates the area of $\mathrm{KCl}$ application to elicit CSD (in the frontal cortex), the two recording points (1 and 2, on the parietal cortex), and the point of placement of the common reference electrode (R, on the nasal bones). Data in this non-published panel (A) are from our previous publication (Guedes et al., 1996). (B) Mean \pm standard deviation of the CSD Propagation velocity (in $\mathrm{mm} / \mathrm{min}$ ) in well-nourished (left panel) and malnourished (right panel) rats. In both nutritional groups, three age subgroups were studied: 40, 120, and 700 days of life. ${ }^{*} p<0.05$ compared with the corresponding 40-day-old group. ${ }^{* *} p<0.05$ compared with the 40-day-and 120 -day-old groups. ${ }^{+} p<0.05$ compared with the corresponding sedentary groups. (C) Recordings of DC slow potential change $(\mathrm{P})$ and electrocorticogram (E) of CSD illustrating failure of CSD propagation in a 700-day-old rat. Note that after being elicited by KCl, CSD reached the recording point 1, but failed to reach point 2. (D) Percentage of KCl-elicited CSD episodes that failed to propagate to the remote recording point (2). ${ }^{*} p<0.05$ compared to the corresponding younger (4-month-old) group. Data in the non-published panels (B,D) are from our previous publication (Batista-de-Oliveira et al., 2012). Traces shown in part C corresponds to panel $\mathbf{B}$ of Figure 3 from the paper by Batista-de-Oliveira et al. (2012). These traces are here reproduced with permission (No. 4532461257722) from the publisher. 
present in organisms under chronic ethanol consumption (Brocardo et al., 2017; Reddy et al., 2017). Using various paradigms of ethanol administration, we investigated the effects of ethanol on CSD propagation in the rat cortex. Initially, we demonstrated that daily ethanol gavage for 7 days or longer (18 days) significantly accelerated CSD (Guedes and Frade, 1993; Abadie-Guedes et al., 2008). In support of the hypothesis of ROS involvement in CSD ethanol effects, a carotenoid extract from shrimp, which is rich in the antioxidant astaxanthin, protected rat brain against the effects of ethanol on CSD (Bezerra et al., 2005). Furthermore, treatment with pure astaxanthin produced the same antagonistic effect of the shrimp carotenoid extract on the ethanol-induced action on CSD in a dose-dependent manner (Abadie-Guedes et al., 2008). In contrast to chronic ethanol treatment and in line with previous data from others (Sonn and Mayevsky, 2001), acute administration of ethanol (single gavage) decelerated CSD, and this effect was antagonized by astaxanthin (Abadie-Guedes et al., 2012). More recently, we demonstrated that the noncarotenoid antioxidant alpha-tocopherol also antagonizes the effect of ethanol on CSD, suggesting that this antagonistic action is not a particular property of carotenoids (AbadieGuedes et al., 2016). In line with this suggestion, it is interesting to note that another non-carotenoid antioxidant molecule, ascorbic acid, has been shown to modulate CSD (Mendes-da-Silva et al., 2014, 2018).

Within the two age ranges that we investigated (60-80 and 150-180 days), no influence of age on the ethanol-induced action on CSD was observed (Abadie-Guedes et al., 2016). This is illustrated in Supplementary Figure S1. However, it remains to be investigated whether ethanol consumption at more advanced ages would affect CSD features. The hypothesis of an antioxidantbased modulation of CSD effects produced by ethanol shall be further investigated to understand their molecular mechanisms.

\section{Age, Physical Exercise, and CSD Features}

In gerontology, neurological dysfunctions that are causally related to the aging process constitute a matter of increasing concern. Therapies that are based on physical exercise usually produce very positive outcomes (Marcelino et al., 2013; Fattoretti et al., 2018; Morgan et al., 2018). In a previous study (Batista-deOliveira et al., 2012), we investigated whether physical exercise and unfavorable lactation could modulate the age effects on brain electrophysiological signaling, as indexed by CSD. Data are summarized in Figure 1B. Compared with age-mated sedentary controls, exercised animals presented with significantly lower CSD propagation velocity (Figure 1B, left panel). Malnutrition induced by unfavorable lactation modulated the CSD effect of exercise (Figure 1B, right panel). Furthermore, the percentage of propagation failure of $\mathrm{KCl}$-elicited CSD was significantly higher in older compared to younger animals (Figures 1C,D). Using the same unfavorable lactation paradigm, we documented a brain effect of exercise in increasing microglial (Iba1) immunolabeling in cortical tissue (Lima et al., 2014). We also demonstrated agerelated reduced performance in both spatial and object identity recognition tasks, as well as changes in the innate immune system in the brain, with a significant impact on microglial homeostasis in aged rats (Viana et al., 2013).

\section{CSD-Induced Potentiation of Brain Signaling: Does Aging Play a Modulating Role?}

In his pioneer seminal study, Leão noted that during CSD the spontaneously recorded electrocorticographic activity was substituted with abnormal, high-amplitude "epileptiform waves" (Leão, 1944a), suggesting a CSD-related imbalance in neuronal excitability. Five decades later, a post-CSD potentiation of cortical evoked responses was described in vitro (Footitt and Newberry, 1998). This was followed, a few years later, by demonstration of a similar CSD-dependent potentiation in vivo, both in nonmammal and mammal vertebrates, frog (Guedes et al., 2005) and rat (Souza et al., 2011, 2015, 2016; Silva-Gondim et al., 2017), respectively. Supplementary Figure S2 illustrates this potentiation effect in rats that were subjected to swimming exercise at two distinct ages: 8-23 and 60-75 days of life (Silva-Gondim et al., 2017). On average, after fully recovering from CSD, ECoG activity was shown to present a $14 \%$ to $43 \%$ higher amplitude than in the pre-CSD period for the same animal $(p<0.05)$. Early swimming and late swimming reduced and enhanced the post-CSD ECoG potentiation, respectively, compared to the respective non-exercised groups $(p<0.05)$, suggesting a differential effect of age of swimming exercise on CSD-induced ECoG potentiation.

\section{FINAL REMARKS}

\section{Cellular Mechanisms and Physiological Interpretation}

In the aged brain, physiological and pathological conditions can modulate the electrophysiological mechanisms involved in brain signaling (Guedes et al., 1996; Farkas et al., 2011) and brain ability to produce and propagate CSD (Hertelendy et al., 2018). These last authors discussed the possibility that aging may impair physiologic processes such as ion channel function and ion pump activity that can be implicated in elicitation and propagation of CSD. Descriptions of the two-dimensional pattern of CSD propagation, based on magnetoencephalography (Eiselt et al., 2004) and optical imaging recording (Fujita et al., 2016), suggest an inhomogeneity of the cortical tissue, which also include age-related vascular hyporesponsivity and neuronal and glial density changes (Farkas et al., 2011; Hertelendy et al., 2018). These factors could be affected by aging and therefore influence the variability of CSD parameters. Furthermore, changes in the myelination pattern of the cortical tissue have been shown to inversely correlate with the propagation velocity of CSD, which might influence the stabilization and buffering of extracellular ion concentration that is crucial for CSD parameters (e.g., propagation velocity and DC amplitude) and cortical excitability, respectively (Merkler et al., 2009). Taken together, these pieces of evidence suggest that age-related alterations in the structural and functional complexity of the brain could play an important role in modifying CSD features in the aged brain. 


\section{Application of the CSD Model to Investigate Factors That Disturb Normal Neuronal and Glial Functioning}

As we have suggested in this review, experimental data allow us to conclude that CSD represents a useful and very important model to help understand how the brain modifies its functioning under physiological and pathological conditions, although CSD may not be the most appropriate read-out of the age-related adaptation of neuronal function. Because of ethical limitations, CSD studies on the normal human brain are not available so far. Occurrence of CSD in man has been usually reported in patients with severe neurological damage (Hartings et al., 2017; Lauritzen and Strong, 2017). From a translational perspective and within the limitation and caution that the extrapolation of experimental data to the human condition requires, our findings collectively support the hope that understanding CSD mechanisms could facilitate the development of more effective treatments against some aging-associated neurological disorders (Lauritzen et al., 2011). Furthermore, the CSD model might give us valuable insights into the molecular mechanisms through which, in the aged brain, factors such those here discussed (ethanol consumption, malnutrition and physical exercise) can modulate brain signaling. Another factor that shall be investigated in the aged brain using the CSD model is the reportedly beneficial effect of moderate consumption of caffeine-containing beverages, such as coffee, tea and guarana-based drinks (Vila-Luna et al., 2012; Perry et al., 2016; Mingori et al., 2017). Interestingly, recent findings suggest a facilitating effect of caffeine on CSD propagation in the young adult rat (Chagas et al., 2018). The possibility that caffeine ingestion actually represents a way of preventing or at least minimizing age-related brain dysfunction (Cunha and Agostinho, 2010) is an attractive theme that shall be explored in the near future. The relevance of this point can be viewed as very substantial when we consider, as highlighted in the introduction of this article, that the proportion of the human population that is affected by age-related neurological diseases is increasing over the last decades. Minimizing the negative consequences of brain aging on the quality of human life is a valuable goal that is worth being scientifically pursued.

\section{AUTHOR CONTRIBUTIONS}

RG and RA-G participated in all phases of conceiving, discussing, and writing this mini-review.

\section{REFERENCES}

Abadie-Guedes, R., Bezerra, R. S., and Guedes, R. C. A. (2016). Alpha-tocopherol counteracts the effect of ethanol on cortical spreading depression in rats of various ages, with and without ethanol abstinence. Alcohol. Clin. Exp. Res. 40, 728-733. doi: 10.1111/acer.12998

Abadie-Guedes, R., Guedes, R. C. A., and Bezerra, R. S. (2012). The impairing effect of acute ethanol on spreading depression is antagonized by astaxanthin in rats of two young-adult ages. Alcohol. Clin. Exp. Res. 36, 1563-1567. doi: $10.1111 / \mathrm{j} .1530-0277.2012 .01766 . x$

\section{FUNDING}

Funding for this project was provided by Coordenação de Aperfeiçoamento de Pessoal de Nível Superior - Brazil (CAPES Procad 2007, Ciências do Mar 2009 and BEX 2036/15-0) Finance Code 001.

\section{ACKNOWLEDGMENTS}

The authors thank the Brazilian agencies Instituto Nacional de Ciência e Tecnologia em Excitotoxicidade e Neuroproteção, and $\mathrm{CNPq}(445101 / 2014-8$ and 475787/2009-9), for financial support. RG is a Research Fellow from $\mathrm{CNPq}$ (No. 303636/2014-9).

\section{SUPPLEMENTARY MATERIAL}

The Supplementary Material for this article can be found online at: https://www.frontiersin.org/articles/10.3389/fnagi. 2019.00136/full\#supplementary-material

FIGURE S1 | CSD features in ethanolcc-treated Wistar rats of different ages. (A) recording of the slow DC potential change that is typical from CSD. Recordings are from two rats with 3 months (upper traces) and 6 months of life (lower traces). CSD was elicited by 1-min application (at the time marked with a black horizontal bar under trace 1) of a cotton ball (1-2 mm diameter) soaked in $\mathrm{KCl} 2 \%$ solution. One can note, in the older animal, the longer latency for a CSD wave to cross the interelectrode distance, indicating lower velocity, compared with the younger rat. (B) skull diagram showing the place of the reference electrode $(R)$ on the nasal bones, the $\mathrm{KCl}$ application site $(\mathrm{KCl})$ on the frontal bone, and the recording points 1 and 2 on the parietal bone. (C) velocity of CSD propagation in 3-months old (white bars) and 6-months old (gray bars) Wistar rats that were treated with water (control group) or $3 \mathrm{~g} / \mathrm{kg}$ ethanol for 21 days. Data are expressed as mean \pm standard deviation. ${ }^{*} p<0.05$, ethanol group different from the water group. ${ }^{\#} p<0.05$, 6-months old different from the 3-months old group. This unpublished figure is based on data from our previously published papers (Abadie-Guedes et al., 2012, 2016).

FIGURE S2 | Examples of Electrocorticogram (ECOG) from three Wistar rats that are representative of the control group and two groups that were subjected to swimming exercise early in life (P8-P23), or late in life (P60-P75). ECoG after CSD presents higher amplitude compared with the 'before CSD' traces. This unpublished figure is based on data from our previously paper (Silva-Gondim et al., 2017).

TABLE S1 | Examples of Brain morphological and physiological features that change as a function of aging.

Abadie-Guedes, R., Santos, S. D., Cahú, T. B., Guedes, R. C. A., and Bezerra, R. S (2008). Dose-dependent effects of astaxanthin on cortical spreading depression in chronically ethanol-treated adult rats. Alcohol. Clin. Exp. Res. 32, 1417-1421. doi: 10.1111/j.1530-0277.2008.00710.x

Anguera, J. A., and Gazzaley, A. (2012). Dissociation of motor and sensory inhibition processes in normal aging. Clin. Neurophysiol. 123, 730-740. doi: 10.1016/j.clinph.2011.08.024

Asadi-Pooya, A. A., Dlugos, D., Skidmore, C., and Sperling, M. R. (2017). Atlas of Electroencephalography, 3rd Edn. Philadelphia, PA: Thomas Jefferson University. 
Barreto, G. E., Capani, F., and Cabezas, R. (2014). Cortical spreading depression and mitochondrial dysfunction with aging: lessons from ethanol abuse. Front. Aging Neurosci. 6:117. doi: 10.3389/fnagi.2014.00117

Batista-de-Oliveira, M., Lopes, A. A. C., Mendes-da-Silva, R. F., and Guedes, R. C. A. (2012). Aging-dependent brain electrophysiological effects in rats after distinct lactation conditions, and treadmill exercise: a spreading depression analysis. Exp. Gerontol. 47, 452-457. doi: 10.1016/j.exger.2012.03.016

Bell, R. D., Winkler, E. A., Sagare, A. P., Singh, I., LaRue, B., Deane, R., et al. (2010). Pericytes control key neurovascular functions and neuronal phenotype in the adult brain and during brain aging. Neuron 68, 409-427. doi: 10.1016/j.neuron. 2010.09 .043

Bernard, J. A., and Seidler, R. D. (2014). Moving forward: age effects on the cerebellum underlie cognitive and motor declines. Neurosci. Biobehav. Rev. 42, 193-207. doi: 10.1016/j.neubiorev.2014.02.011

Bezerra, R. S., Abadie-Guedes, R., Melo, F. R. M., Paiva, A. M. A., Amânciodos-Santos, A., and Guedes, R. C. A. (2005). Shrimp carotenoids protect the developing rat cerebral cortex against the effects of ethanol on cortical spreading depression. Neurosci. Lett. 391, 51-55. doi: 10.1016/j.neulet.2005.08.040

Bourisly, A., and Shuaib, A. (2018). Neurophysiological effects of aging: a P200 ERP study. Translat. Neurosci. 9, 61-66. doi: 10.1515/tnsci-2018-0011

Brocardo, P. S., Gil-Mohapel, J., Wortman, R., Noonan, A., McGinnis, E., Patten, A. R., et al. (2017). The effects of ethanol exposure during distinct periods of brain development on oxidative stress in the adult rat brain. Alcohol. Clin. Exp. Res. 41, 26-37. doi: 10.1111/acer.13266

Carvalho, C., and Moreira, P. I. (2018). Oxidative stress: a major player in cerebrovascular alterations associated to neurodegenerative events. Front. Physiol. 9:806. doi: 10.3389/fphys.2018.00806

Chagas, C. L., Benevides, R. D. L., Bezerra, C. M. S., Abadie-Guedes, R., and Guedes, R. C. A. (2018). Ponderal, behavioral and brain electrophysiological effects of caffeine on the immature rat. J. Caff. Aden. Res. 8, 1-9. doi: 10.1089/ caff.2018.0009

Clark, D., Institoris, A., Kozák, G., Bere, Z., Tuor, U., Farkas, E., et al. (2014). Impact of aging on spreading depolarizations induced by focal brain ischemia in rats. Neurobiol. Aging 35, 2803-2811. doi: 10.1016/j.neurobiolaging.2014.06.013

Coskren, P. J., Luebke, J. I., Kabaso, D., Wearne, S. L., Yadav, A., Rumbell, T., et al. (2015). Functional consequences of age-related morphologic changes to pyramidal neurons of the rhesus monkey prefrontal cortex. J. Comput. Neurosci. 38, 263-283. doi: 10.1007/s10827-014-0541-5

Cunha, R. A., and Agostinho, P. M. (2010). Chronic caffeine consumption prevents memory disturbance in different animal models of memory decline. J. Alzheimers Dis. 20(Suppl. 1), S95-S116. doi: 10.3233/JAD-2010-1408

Dreier, J. P., Major, S., Foreman, B., Winkler, M. K. L., Kang, E.-J., Milakara, D., et al. (2018). Terminal spreading depolarization and electrical silence in death of human cerebral cortex. Ann. Neurol. 83, 295-310. doi: 10.1002/ana.25147

Dreier, J. P., Major, S., Manning, A., Woitzik, J., Drenckhahn, C., Steinbrink, J., et al. (2009). Cortical spreading ischaemia is a novel process involved in ischaemic damage in patients with aneurysmal subarachnoid haemorrhage. Brain 132, 1866-1881. doi: 10.1093/brain/awp102

Dreier, J. P., Woitzik, J., Fabricius, M., Bhatia, R., Major, S., Drenckhahn, C., et al. (2006). Delayed ischaemic neurological deficits after subarachnoid haemorrhage are associated with clusters of spreading depolarizations. Brain 129, 3224-3237. doi: 10.1093/brain/awl297

Eiselt, M., Gießler, F., Platzek, D., Haueisen, J., Zwiener, U., and Röther, J. (2004). Inhomogeneous propagation of cortical spreading depression-detection by electro- and magnetoencephalography in rats. Brain Res. 1028, 83-91. doi: 10.1016/j.brainres.2004.09.002

El-Bachá, R. S., Lima-Filho, J. L., and Guedes, R. C. A. (1998). Dietary antioxidant deficiency facilitates cortical spreading depression induced by photo-activated riboflavin. Nutr. Neurosci. 1, 205-212. doi: 10.1080/1028415x.1998.11747230

Fabricius, M., Fuhr, S., Bhatia, R., Boutelle, M., Hashemi, P., Strong, A. J., et al. (2006). Cortical spreading depression and peri-infarct depolarization in acutely injured human cerebral cortex. Brain 129, 778-790. doi: 10.1093/brain/awh716

Farkas, E., and Bari, F. (2014). Spreading depolarization in the ischemic brain: does aging have an impact? J. Gerontol. A Biol. Sci. Med. Sci. 69, 1363-1370. doi: 10.1093/gerona/glu066

Farkas, E., Obrenovitch, T. P., Institóris, A., and Bari, F. (2011). Effects of early aging and cerebral hypoperfusion on spreading depression in rats. Neurobiol. Aging 32, 1707-1715. doi: 10.1016/j.neurobiolaging.2009.10.002
Fattoretti, P., Malatesta, M., Cisterna, B., Milanese, C., and Zancanaro, C. (2018). Modulatory effect of aerobic physical activity on synaptic ultrastructure in the old mouse hippocampus. Front. Aging Neurosci. 10:141. doi: 10.3389/fnagi. 2018.00141

Footitt, D. R., and Newberry, N. R. (1998). Cortical spreading depression induces an LTP-like effect in rat neocortex in vitro. Brain Res. 781, 339-342. doi: 10.1016/s0006-8993(97)01359-0

Fujita, S., Mizoguchi, N., Aoki, R., Cui, Y., Koshikawa, N., and Kobayashi, M. (2016). Cytoarchitecture-dependent decrease in propagation velocity of cortical spreading depression in the rat insular cortex revealed by optical imaging. Cereb. Cortex 26, 1580-1589. doi: 10.1093/cercor/ bhu336

Guedes, R. C. A. (2005). "Electrophysiological methods: application in nutritional neuroscience," in Nutritional Neurosciences: Overview of an Emerging Field, eds H. Liebermann, R. Kanarek, and C. Prasad (New York, NY: CRC Press), 39-54.

Guedes, R. C. A. (2011). "Cortical spreading depression: a model for studying brain consequences of malnutrition," in Handbook of Behavior, Food and Nutrition, eds V. R. Preedy, R. R. Watson, and C. R. Martin (London: Springer), 2343-2355. doi: 10.1007/978-0-387-92271-3_148

Guedes, R. C. A., Amorim, L. F., and Teodósio, N. R. (1996). Effect of aging on cortical spreading depression. Braz. J. Med. Biol. Res. 29, 1407-1412.

Guedes, R. C. A., Araújo, M. G. R., Verçosa, T. C., Bion, F. M., Sá, A. L., Pereira, A. Jr., et al. (2017). Evidence of an inverse correlation between serotonergic activity and spreading depression propagation in the rat cortex. Brain Res. 1672, 29-34. doi: 10.1016/j.brainres.2017.07.011

Guedes, R. C. A., Bezerra, R. S., and Abadie-Guedes, R. (2016). "Ethanol and its impact on the brain's electrical activity," in Neuropathology of Drug Addictions and Substance Misuse, ed. V. R. Preedy (London: Elsevier), 1-9.

Guedes, R. C. A., and Cavalheiro, E. A. (1997). Blockade of spreading depression in chronic epileptic rats: reversion by diazepam. Epilepsy Res. 27, 33-40. doi: 10.1016/s0920-1211(96)01017-0

Guedes, R. C. A., and Frade, S. F. (1993). Effect of ethanol on cortical spreading depression. Braz. J. Med. Biol. Res. 26, 1241-1244.

Guedes, R. C. A., Tsurudome, K., and Matsumoto, N. (2005). Spreading depression in vivo potentiates electrically-driven responses in frog optic tectum. Brain Res. 1036, 109-114. doi: 10.1016/j.brainres.2004. 12.033

Guillemin, G. J., Essa, M. M., Song, B.-J., and Manivasagam, T. (2017). Dietary supplements/antioxidants: impact on redox status in brain diseases. Oxidat. Med. Cell. Longev. 2017:5048432. doi: 10.1155/2017/5048432

Guo, S., Deng, W., Xing, C., Zhou, Y., Ning, M., and Lo, E. H. (2018). Effects of aging, hypertension and diabetes on the mouse brain and heart vasculomes. Neurobiol. Dis. 126, 117-123. doi: 10.1016/j.nbd.2018.07.021

Hartings, J. A., Shuttleworth, C. W., Kirov, S. A., Ayata, C., Hinzman, J. M., Foreman, B., et al. (2017). The continuum of spreading depolarizations in acute cortical lesion development: examining Leão’s legacy. J. Cereb. Blood Flow Metab. 37, 1571-1594. doi: 10.1177/0271678X166 54495

Hartings, J. A., Strong, A. J., Fabricius, M., Manning, A., Bhatia, R., Dreier, J. P., et al. (2009). Spreading depolarizations and late secondary insults after traumatic brain injury. J. Neurotrauma 26, 1857-1866. doi: 10.1089/neu.20090961

Hartings, J. A., Watanabe, T., Bullock, M. R., Okonkwo, D. O., Fabricius, M., Woitzik, J., et al. (2011). Spreading depolarizations have prolonged direct current shifts and are associated with poor outcome in brain trauma. Brain 134(Pt. 5), 1529-1540. doi: 10.1093/brain/awr048

Hernandez, C. M., McQuail, J. A., Schwabe, M. R., Burke, S. N., Setlow, B., and Bizon, J. L. (2018). Age-related declines in prefrontal cortical expression of metabotropic glutamate receptors that support working memory. Eneuro 5:ENEURO.0164-18. doi: 10.1523/ENEURO.0164-18

Hertelendy, P., Menyhárt, A., Makra, P., Süle, Z., Kiss, T., Tóth, G., et al. (2017). Advancing age and ischemia elevate the electric threshold to elicit spreading depolarization in the cerebral cortex of young adult rats. J. Cereb. Blood Flow Metab. 37, 1763-1775. doi: 10.1177/0271678X166 43735

Hertelendy, P., Varga, D. P., Menyhárt, A., Bari, F., and Farkas, E. (2018). Susceptibility of the cerebral cortex to spreading depolarization in neurological 
disease states: the impact of aging. Neurochem. Int. doi: 10.1016/j.neuint.2018. 10.010 [Epub ahead of print].

Ibáñez-Contreras, A., Hernández-Arciga, U., Poblano, A., Arteaga-Silva, M., Hernández-Godínez, B., Mendoza-Cuevas, G., et al. (2018). Electrical activity of sensory pathways in female and male geriatric Rhesus monkeys (Macaca mulatta), and its relation to oxidative stress. Exp. Gerontol. 101, 80-94. doi: 10.1016/j.exger.2017.11.003

Lauritzen, M. (1987). Cerebral blood flow in migraine and cortical spreading depression. Acta Neurol. Scand. Suppl. 113, 1-40.

Lauritzen, M., Dreier, J. P., Fabricius, M., Hartings, J. A., Graf, R., and Strong, A. J. (2011). Clinical relevance of cortical spreading depression in neurological disorders: migraine, malignant stroke, subarachnoid and intracranial hemorrhage, and traumatic brain injury. J. Cereb. Blood. Flow. Metab. 31, 17-35. doi: 10.1038/jcbfm.2010.191

Lauritzen, M., and Strong, A. J. (2017). 'Spreading depression of Leão' and its emerging relevance to acute brain injury in humans. J. Cereb. Blood Flow Metab. 37, 1553-1570. doi: 10.1177/0271678x16657092

Leão, A. A. P. (1944a). Spreading depression of activity in the cerebral cortex. J. Neurophysiol. 7, 359-390. doi: 10.1152/jn.1944.7.6.359

Leão, A. A. P. (1944b). Pial circulation and spreading depression of activity in the cerebral cortex. J. Neurophysiol. 7, 391-396. doi: 10.1152/jn.1944.7.6.391

Leão, A. A. P. (1947). Further observations on the spreading depression of activity in the cerebral cortex. J. Neurophysiol. 10, 409-414. doi: 10.1152/jn.1947.10.6.409

Lima, C. B., Soares, G. S. F., Vitor, S. M., Andrade-da-Costa, B. L. S., Castellano, B., and Guedes, R. C. A. (2014). Spreading depression features and Iba1 immunoreactivity in the cerebral cortex of developing rats submitted to treadmill exercise after treatment with monosodium glutamate. Int. J. Dev. Neurosci. 33, 98-105. doi: 10.1016/j.ijdevneu.2013.12.008

Marcelino, T. B., Longoni, A., Kudo, K. Y., Stone, V., Rech, A., Assis, A. M., et al. (2013). Evidences that maternal swimming exercise improves antioxidant defenses and induces mitochondrial biogenesis in the brain of young Wistar rats. Neuroscience 246, 28-39. doi: 10.1016/j.neuroscience.2013.04.043

McKetton, L., Sobczyk, O., Duffin, J., Poublanc, J., Sam, K., Crawley, A. P., et al. (2018). The aging brain and cerebrovascular reactivity. Neuroimage 181, 132-141. doi: 10.1016/j.neuroimage.2018.07.007

Mendes-da-Silva, R. F., Cunha-Lopes, A. A., Bandim-da-Silva, M. E., Cavalcanti, G. A., Rodrigues, A. R. O., Andrade-da-Costa, B. L. S., et al. (2014). Prooxidant versus antioxidant brain action of ascorbic acid in well-nourished and malnourished rats as a function of dose: a cortical spreading depression and malondialdehyde analysis. Neuropharmacology 86, 155-160. doi: 10.1016/j. neuropharm.2014.06.027

Mendes-da-Silva, R. F., Francisco, E. S., and Guedes, R. C. A. (2018). Pilocarpine/ascorbic acid interaction in the immature brain: Electrophysiological and oxidative effects in well-nourished and malnourished rats. Brain Res. Bull. 142, 414-421. doi: 10.1016/j.brainresbull.2018. 09.008

Menyhárt, Á., Makra, P., Szepes, B. É, Tóth, O. M., Hertelendy, P., Bari, F., et al. (2015). High incidence of adverse cerebral blood flow responses to spreading depolarization in the aged ischemic rat brain. Neurobiol. Aging 36, 3269-3277. doi: 10.1016/j.neurobiolaging.2015.08.014

Menyhárt, Á., Zölei-Szénási, D., Puskás, T., Makra, P., Bari, F., and Farkas, E. (2017). Age or ischemia uncouples the blood flow response, tissue acidosis, and direct current potential signature of spreading depolarization in the rat brain. Am. J. Physiol. Heart Circ. Physiol. 313, H328-H337. doi: 10.1152/ajpheart. 00222.2017

Merkler, D., Klinker, F., Jürgens, T., Glaser, R., Paulus, W., Brinkmann, B. G., et al. (2009). Propagation of spreading depression inversely correlates with cortical myelin content. Ann. Neurol. 66, 355-365. doi: 10.1002/ana. 21746

Mesgari, M., Krüger, J., Riemer, C. T., Ghadiri, M. K., Kovac, S., and Gorji, A. (2017). Gabapentin prevents cortical spreading depolarization-induced disinhibition. Neuroscience 361, 1-5. doi: 10.1016/j.neuroscience.2017.08.009

Mingori, M. R., Heimfarth, L., Ferreira, C. F., Gomes, H. M., Moresco, K. S., Delgado, J., et al. (2017). Effect of Paullinia cupana Mart. commercial extract during the aging of middle age Wistar rats: differential effects on the hippocampus and striatum. Neurochem. Res. 42, 2257-2273. doi: 10.1007/ s11064-017-2238-4
Morgan, J. A., Singhal, G., Corrigan, F., Jaehne, E. J., Jawahar, M. C., and Baune, B. T. (2018). TNF signalling via the TNF receptors mediates the effects of exercise on cognition-like behaviours. Behav. Brain Res. 353, 74-82. doi: 10. 1016/j.bbr.2018.06.036

Netto, M., and Martins-Ferreira, H. (1989). Elicitation of spreading depression by rose bengal photodynamic action. Photochem. Photobiol. 50, 229-234. doi: 10.1111/j.1751-1097.1989.tb04153.x

Perry, C. S., Thomas, A. K., Taylor, H. A., Jacques, P. F., and Kanarek, R. B. (2016). The impact of caffeine use across the lifespan on cognitive performance in elderly women. Appetite 107, 69-78. doi: 10.1016/j.appet.2016. 07.028

Reddy, V. D., Padmavathi, P., Bulle, S., Hebbani, A. V., Marthadu, S. B., Venugopalacharyulu, N. C., et al. (2017). Association between alcohol-induced oxidative stress and membrane properties in synaptosomes: a protective role of vitamin E. Neurotoxicol. Teratol. 63, 60-65. doi: 10.1016/j.ntt.2017. 07.004

Sadeghian, H., Lacoste, B., Qin, T., Toussay, X., Rosa, R., Oka, F., et al. (2018). Spreading depolarizations trigger caveolin-1-dependent endothelial transcytosis. Ann. Neurol. 84, 409-423. doi: 10.1002/ana.25298

Schliebs, R., and Arendt, T. (2011). The cholinergic system in aging and neuronal degeneration. Behav. Brain. Res. 221, 555-563. doi: 10.1016/j.bbr.2010.11.058

Seals, D. R., Kaplon, R. E., Gioscia-Ryan, R. A., and LaRocca, T. J. (2014). You're only as old as your arteries: translational strategies for preserving vascular endothelial function with aging. Physiology 29, 250-264. doi: 10.1152/physiol. 00059.2013

Silva-Gondim, M. B., Souza, T. K. M., Rodrigues, M. C. A., and Guedes, R. C. A. (2017). Suckling in litters with different sizes, and early and late swimming exercise differentially modulates anxiety-like behavior, memory and electrocorticogram potentiation after spreading depression in rats. Nutr. Neurosci. 22, 464-473. doi: 10.1080/1028415X.2017.14 07472

Sonn, J., and Mayevsky, A. (2001). The effect of ethanol on metabolic, hemodynamic and electrical responses to cortical spreading depression. Brain Res. 908, 174-186. doi: 10.1016/s0006-8993(01)0 2643-9

Sousa, M. S. B., Holanda, I. M. S., Monteiro, H. M. C., and Amâncio-Dos-Santos, Â. (2018). Antioxidant extract counteracts the effects of aging on cortical spreading depression and oxidative stress in the brain cortex. Acta Cir. Bras. 33, 472-482. doi: 10.1590/s0102-865020180060000001

Souza, T. K. M., Barros-e-Silva, M., Gomes, A. R., Oliveira, H. M., Moraes, R. B., Barbosa, C. T. F., et al. (2011). Potentiation of spontaneous and evoked cortical electrical activity after spreading depression: in vivo analysis in well-nourished and malnourished rats. Exp. Brain Res. 214, 463-469. doi: 10.1007/s00221-0112844-3

Souza, T. K. M., Silva-Gondim, M. B., Rodrigues, M. C. A., and Guedes, R. C. A. (2015). Anesthetic agents modulate ECoG potentiation after spreading depression, and insulin-induced hypoglycemia does not modify this effect. Neurosci. Lett. 592, 6-11. doi: 10.1016/j.neulet.2015.02.018

Souza, T. K. M., Silva-Gondim, M. B., Rodrigues, M. C. A., and Guedes, R. C. A. (2016). The facilitating effect of unfavorable lactation on the potentiation of electrocorticogram after spreading depression in awake and anesthetized adult rats. Nutr. Neurosci. 21, 16-24. doi: 10.1080/1028415X.2016.12 10878

Takano, K., Latour, L. L., Formato, J. E., Carano, R. A., Helmer, K. G., Hasegawa, Y., et al. (1996). The role of spreading depression in focal ischemia evaluated by diffusion mapping. Ann. Neurol. 39, 308-318. doi: 10.1002/ana.4103 90307

Torrente, D., Cabezas, R., Avila, M. F., García-Segura, L. M., Barreto, G. E., and Guedes, R. C. A. (2014). Cortical spreading depression in traumatic brain injuries: Is there a role for astrocytes? Neurosci. Lett. 565, 2-6. doi: 10.1016/j. neulet.2013.12.058

Viana, L. C., Lima, C. M., Oliveira, M. A., Borges, R. P., Cardoso, T. T., Almeida, I. N. F., et al. (2013). Litter size, age-related memory impairments, and microglial changes in rat dentate gyrus: stereological analysis and three dimensional morphometry. Neuroscience 238, 280-296. doi: 10.1016/j. neuroscience.2013.02.019

Vila-Luna, S., Cabrera-Isidoro, S., Vila-Luna, L., Juárez-Díaz, I., Bata-García, J. L., Alvarez-Cervera, F. J., et al. (2012). Chronic caffeine consumption prevents 
cognitive decline from young to middle age in rats, and is associated with increased length, branching, and spine density of basal dendrites in CA1 hippocampal neurons. Neuroscience 202, 384-395. doi: 10.1016/j.neuroscience. 2011.11.053

Vinogradova, L. V. (2018). Initiation of spreading depression by synaptic and network hyperactivity: Insights into trigger mechanisms of migraine aura. Cephalalgia 38, 1177-1187. doi: 10.1177/0333102417 724151

Watson, P., Conroy, A., Moran, G., and Duncan, S. (2012). Retrospective study of sensitivity and specificity of EEG in the elderly compared with younger age groups. Epilepsy Behav. 25, 408-411. doi: 10.1016/j.yebeh.2012. 07.030

World Health Organization [WHO] (2015). World Report on Ageing and Health. Geneva: WHO Press, 260.

Young, W. (1980). Spreading depression in elasmobranch cerebellum. Brain Res. 199, 113-126. doi: 10.1016/0006-8993(80)90234-6
Zhou, Y. F., Li, P. C., Wu, J. H., Haslam, J. A., Mao, L., Xia, Y. P., et al. (2018). Sema3E/PlexinD1 inhibition is a therapeutic strategy for improving cerebral perfusion and restoring functional loss after stroke in aged rats. Neurobiol. Aging 70, 102-116. doi: 10.1016/j.neurobiolaging.2018. 06.003

Conflict of Interest Statement: The authors declare that the research was conducted in the absence of any commercial or financial relationships that could be construed as a potential conflict of interest.

Copyright (c) 2019 Guedes and Abadie-Guedes. This is an open-access article distributed under the terms of the Creative Commons Attribution License (CC BY). The use, distribution or reproduction in other forums is permitted, provided the original author(s) and the copyright owner(s) are credited and that the original publication in this journal is cited, in accordance with accepted academic practice. No use, distribution or reproduction is permitted which does not comply with these terms. 